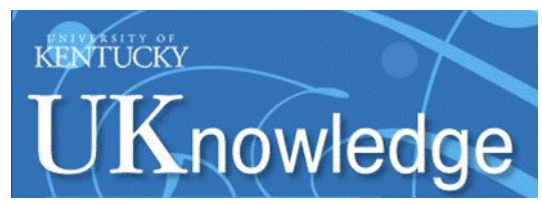

University of Kentucky

UKnowledge

\title{
Impulsive Personality Dimensions Are Associated with Altered Behavioral Performance and Neural Responses in the Monetary Incentive Delay Task
}

\author{
Ruolei Gu \\ Institute of Psychology, China \\ Yang Jiang \\ University of Kentucky, yjiang@uky.edu \\ Seth Kiser \\ University of Kentucky \\ Chelsea L. Black \\ University of Kentucky \\ Lucas S. Broster \\ University of Kentucky, lucas.broster@uky.edu \\ Follow this and additional works at: https://uknowledge.uky.edu/behavsci_facpub
}

¿narext dathe for additionalauthors gy Commons, Behavior and Behavior Mechanisms Commons, and the Psychology Commons

Right click to open a feedback form in a new tab to let us know how this document benefits you.

\section{Repository Citation}

Gu, Ruolei; Jiang, Yang; Kiser, Seth; Black, Chelsea L.; Broster, Lucas S.; Luo, Yue-Jia; and Kelly, Thomas H., "Impulsive Personality Dimensions Are Associated with Altered Behavioral Performance and Neural Responses in the Monetary Incentive Delay Task" (2017). Behavioral Science Faculty Publications. 43. https://uknowledge.uky.edu/behavsci_facpub/43

This Article is brought to you for free and open access by the Behavioral Science at UKnowledge. It has been accepted for inclusion in Behavioral Science Faculty Publications by an authorized administrator of UKnowledge. For more information, please contact UKnowledge@lsv.uky.edu. 


\section{Impulsive Personality Dimensions Are Associated with Altered Behavioral Performance and Neural Responses in the Monetary Incentive Delay Task}

Digital Object Identifier (DOI)

https://doi.org/10.1016/j.neuropsychologia.2017.07.013

Notes/Citation Information

Published in Neuropsychologia, v. 103, p. 59-68.

(c) 2017 Elsevier Ltd. All rights reserved.

This manuscript version is made available under the CC-BY-NC-ND 4.0 license https://creativecommons.org/licenses/by-nc-nd/4.0/.

The document available for download is the author's post-peer-review final draft of the article.

Authors

Ruolei Gu, Yang Jiang, Seth Kiser, Chelsea L. Black, Lucas S. Broster, Yue-Jia Luo, and Thomas H. Kelly 


\title{
Impulsive Personality Dimensions are associated with Altered Behavioral Performance and Neural Responses in the Monetary Incentive Delay Task
}

\author{
Ruolei Gua,b, Yang Jiang ${ }^{c,{ }^{\star},}$, Seth Kiser ${ }^{c, d}$, Chelsea L. Black ${ }^{c, e}$, Lucas S. Brosterc,f ${ }^{c,}$ Yue-jia \\ Luog, and Thomas H. Kellyc \\ ${ }^{a}$ CAS Key Laboratory of Behavioral Science, Institute of Psychology, Beijing, China \\ ${ }^{b}$ Department of Psychology, University of Chinese Academy of Sciences, Beijing, China \\ 'Department of Behavioral Science, University of Kentucky College of Medicine, Lexington, KY, \\ USA \\ dDistrict of Columbia Veteran Affairs Medical Center, Washington, D.C., USA \\ eChildren's National Medical Center, Washington, D.C., USA \\ fDepartment of Psychiatry, University of California at San Francisco, San Francisco, CA, USA \\ Institute of Affective and Social Neuroscience, Shenzhen University, Shenzhen, China
}

\section{Abstract}

\begin{abstract}
Individual differences in dimensions of impulsivity personality including disinhibition and sensation seeking modulate approach responses to reinforcing stimuli, such as drugs and money. The current study examined the effects of monetary incentive on both behavioral performance and electrophysiological activity among individuals varying in disinhibition and sensation seeking. The monetary incentive delay (MID) task was completed under electroencephalogram (EEG) recording. Behavioral data showed that higher disinhibition and sensation-seeking were associated with lower performance accuracy. Event-related potential (ERP) data showed that high reinforcement cues elicited a larger late positive component (LPC) than other conditions among high disinhibition participants, indicating its strong emotional influence. Additionally, in the neutral incentive condition, the feedback-related negativity (FRN) elicited by correct outcomes was larger than that elicited by incorrect outcomes in the high disinhibition group, only. This novel finding indicates that high disinhibition participants were less likely to expect correct outcomes
\end{abstract}

\footnotetext{
"Editorial Correspondence should be sent to: 113 Medical Behavioral Science Building, University of Kentucky College of Medicine, Lexington, KY 40536. Tel.: (859) 257-2122. yjiang@uky.edu.

Conflict of Interest

The authors declare no conflict of interest.

Author Contributions

Conceived and designed the experiments: YJ, THK. Performed the experiments: SK, CB, LSB. Analyzed the data: RG, SK. Wrote the manuscript: RG, YJ, YJL, THK.

Publisher's Disclaimer: This is a PDF file of an unedited manuscript that has been accepted for publication. As a service to our customers we are providing this early version of the manuscript. The manuscript will undergo copyediting, typesetting, and review of the resulting proof before it is published in its final citable form. Please note that during the production process errors may be discovered which could affect the content, and all legal disclaimers that apply to the journal pertain.
} 
compared to incorrect outcomes in the neutral incentive condition. Finally, the P3 component elicited by outcome presentation showed an interaction between two impulsivity dimensions; when disinhibition level was low, the P3 was larger among high than low sensation seeking participants.

\section{Keywords}

impulsivity; monetary incentive delay (MID) task; event-related potential (ERP); feedback-related negativity (FRN); P3 component; late positive component (LPC)

Risk-related behaviors, such as drug use, gambling, and risky sexual activity, occur in contexts in which the consequences may be reinforcing, punishing, or both, and the probabilities of the outcomes are uncertain (Loewenstein, Weber, Hsee, \& Welch, 2001). For example, the chemical composition of drugs, which determines both reinforcing efficacy and the possibility of untoward response (e.g., allergic reaction, overdose) is often unpredictable, particularly if drugs are acquired from an unknown or illicit source. Uncertain adverse legal and social consequences are also associated with drug possession (Macleod et al., 2004). Gambling is defined by uncertain financial consequences (Fiorillo, Tobler, \& Schultz, 2003). Health risks associated with risky sexual behavior are often difficult to predict (Hill, Ross, \& Low, 1997). It is clear that the decision to engage in risk-related behaviors reflect a confluence of approach and avoidance processes.

Individual differences in the probability of engaging in risk-related behavior have been associated with impulsivity (L. E. Martin \& Potts, 2009), which is characterized by the increased seeking of immediate reward, a reduced delay tolerance, and an inability to plan ahead (Diekhof et al., 2012). High impulsive individuals are at increased health risk due to their participations in risky activities, such as illegal drug abuse, skydiving, and sexual experimentation (Dalley, Everitt, \& Robbins, 2011; Ersche, Turton, Pradhan, Bullmore, \& Robbins, 2010; Jiang et al., 2009; Joseph, Liu, Jiang, Lynam, \& Kelly, 2009). Higher levels of impulsivity are associated with hypersensitivity to reward but hyposensitivity to punishment; in other words, both approach and avoidance processes play important roles in impulsivity (Bari \& Robbins, 2013). There is a growing consensus that impulsivity is a multidimensional construct, but the precise number of its facets is still debated (Gullo, Loxton, \& Dawe, 2014). In this paper, we follow the suggestion of two-factor theoretical models (e.g., Dalley et al., 2011; Dawe, Gullo, \& Loxton, 2004) and decompose impulsivity into two global dimensions, which are labeled as disinhibition (or 'rash impulsiveness') and sensation seeking based on our previous studies (Harvanko, Martin, Lile, Kryscio, \& Kelly, 2016; Perry et al., 2010). Disinhibition refers to a tendency to engage in rash, spontaneous behavior regardless of potential risk or harmful outcomes (Dalley et al., 2011), while sensation seeking is defined as a tendency to seek out novel and thrilling experiences along with the willingness to take risks (Ersche et al., 2010; Fischer \& Smith, 2004). Disinhibition and sensation seeking modulate the influence of drug on behavioral performances, including the enhanced attention toward drug-related cues, the inability to resist drug cravings, and the lack of forethought about negative consequences (Dalley et al., 2011; Harvanko et al., 2016; Kelly et al., 2006; Marusich, Darna, Charnigo, Dwoskin, \& Bardo, 2011). Our previous 
research has demonstrated that individual difference in response to reinforcing stimuli such as food, drugs, and money, is linked to impulsive personality dimensions (e.g., Jiang et al., 2009; Joseph et al., 2009; Kelly et al., 2006; S. B. Martin et al., 2007; Perry et al., 2010). The purpose of this study is to investigate the relationship between behavioral performance on a task involving both reinforcing and avoidance consequences and individual differences in disinhibition and sensation seeking.

To test brain responses to incentive stimuli among individuals varying in impulsivity, we applied a version of the monetary incentive delay (MID) task (Knutson, Adams, Fong, \& Hommer, 2001; Knutson, Westdorp, Kaiser, \& Hommer, 2000), which is adapted from nonhuman primate research on motivation (Schultz, Tremblay, \& Hollerman, 1998) and has been examined extensively in human studies (for a review, see Balodis \& Potenza, 2014). This task was designed to investigate the effect of monetary gains and losses on cognitive function by providing various incentive cues (Samanez-Larkin et al., 2007). In this task, participants are asked to respond as quickly as possible to the appearance of a target. Prior to target presentation, incentive cues indicate the context of the current trial, that is, whether participants could earn money or avoid losses by responding within a limited time window. The MID task has been used successfully to examine individual differences (e.g., depression, alcohol dependence, ageing) in incentive processing (Bjork, Hommer, Grant, \& Danube, 2004; Bjork, Knutson, et al., 2004; Bjork, Knutson, \& Hommer, 2008; Joseph et al., 2015; Knutson, Bhanji, Cooney, Atlas, \& Gotlib, 2008; Samanez-Larkin et al., 2007).

Event-related potential (ERP) reflects the summation of post-synaptic potentials time-locked to an event of interest, collecting from the electrodes placed at the scalp (Amodio, Bartholow, \& Ito, 2014). ERP biomarkers are useful tools to aid our understanding of brain mechanism associated with incentive processing (Kamarajan et al., 2008; L. E. Martin \& Potts, 2004) and they are valuable for investigating individual difference in this process (L. E. Martin \& Potts, 2004, 2009). In the current study, three ERP components are selected as electrophysiological measures, not only because of their importance in the processing of incentive stimuli (San Martín, 2012), but also because of the results of previous studies which used the MID task for ERP research (Broyd et al., 2012; Pfabigan et al., 2015). According to their sequence in time, these components are feedback-related negativity (FRN), P3, and late positive component (LPC), respectively.

A dominant theory is that the FRN represents the decoding of reinforcement value of outcome feedback, such that unfavorable outcomes elicit a larger FRN than favorable outcomes (Holroyd \& Coles, 2002; Nieuwenhuis, Holroyd, Mol, \& Coles, 2004). However, recent studies based on the predicted response outcome (PRO) model contend that the FRN reflects the unexpectness/surprisingness of an event regardless of its favorableness, which means the amplitude of this component is generally larger for unexpected events than for expected ones (Ferdinand, Mecklinger, Kray, \& Gehring, 2012). This viewpoint has received lots of support in the recent literature (Garofalo, Maier, \& di Pellegrino, 2014; Hauser et al., 2014; Sambrook \& Goslin, 2014; Talmi, Atkinson, \& El-Deredy, 2013).

Following the FRN peak, the $\mathrm{P} 3$ is a well-studied component that has been associated with various cognitive functions including attention allocation, memory updating, and stimulus 
evaluation (Polich, 2007; Polich \& Criado, 2006). Generally, the interpretation of the P3 function is highly context-dependent. In decision-making studies, the P3 has often been linked to the motivational significance of the ongoing event (Nieuwenhuis, Aston-Jones, \& Cohen, 2005; San Martín, 2012). Heightened P3 amplitudes indicate stronger motivational impact of an outcome (Polezzi, Sartori, Rumiati, Vidotto, \& Daum, 2010). Consistent with this interpretation, the $\mathrm{P} 3$ amplitude increased in individuals who attributed more meaning to outcomes (De Bruijn, Mars, \& Hulstijn, 2004) or showed stronger desire for rewards (Zheng et al., 2010).

Finally, although not typically studied in the context of decision-making, the LPC is also sensitive to the processing of incentive stimuli. This component, which emerges in a relatively late time window, is suggested to reflect sustained emotional experience to a stimulus (Hajcak, Dunning, \& Foti, 2009; Hajcak \& Olvet, 2008). In decision-making studies, reward-predicting cues elicit a larger LPC than non-reward cues. The same LPC pattern was observed when comparing outcome feedback following reward cues with that following non-reward cues. Lastly, emotional up-regulation strengthens the aforementioned effects (Langeslag \& van Strien, 2013; Pornpattananangkul \& Nusslock, 2015). These findings indicate that the LPC amplitude increases as a function of emotional experience to incentive stimuli (Pornpattananangkul \& Nusslock, 2015).

Broyd et al. (2012) first examined the ERPs in the MID task and suggested that the ERP components generally showed their typical patterns. Specifically, the FRN was larger following monetary loss, and the P3 was enhanced in both incentive conditions (gain/loss) than the neutral condition (Broyd et al., 2012; see also Flores, Munte, \& Donamayor, 2015; K. D. Novak \& Foti, 2015). In contrast, Pfabigan et al. (2014) reported that the P3 elicited by gain cues was larger than both loss and neutral cues, while the latter two condition showed no difference (see also Vignapiano et al., 2016). Additionally, Pfabigan et al. (2015) found that the FRN elicited by the neutral outcome is sensitive to its unexpectedness modulated by cues. Finally, the LPC elicited by MID feedback denoting monetary gain or successfully avoiding monetary loss is larger than non-reward feedback (Broyd et al., 2012). In short, the validity of the FRN, P3, and LPC as neural makers of incentive processing has been established with the MID task. Most relevant to the current study, Novak, Novak, Lynam, and Foti (2016) discovered that in the MID task, sensation seeking scores were positively correlated with the outcome-FRN amplitude, but negatively correlated with the cue-P3 amplitude across incentive conditions. However, only the P3 elicited by cues and the FRN and P3 elicited by outcomes were analyzed. A more comprehensive analysis of ERP signals during the course of the MID task may lead to novel findings about impulsivity dimensions.

We expected to observe individual difference on MID task performance as a function of both disinhibition and sensation seeking status. First, participants high in disinhibition might find it difficult to inhibit behavioral reactions at inappropriate timepoints (see also Goudriaan, Oosterlaan, De Beurs, \& Van Den Brink, 2008). In addition, high disinhibition participants may also show a larger FRN in response to MID feedback because they tend to act rashly without consideration of consequences, and therefore would be more likely to receive unexpected feedback. This hypothesis is supported by the positive correlation between the 
FRN amplitude and disinhibition in previous research (Balconi \& Crivelli, 2010).

Meanwhile, both incentive cue processing and outcome evaluation would vary based on sensation seeking status. Specifically, we predicted that high incentive cues and/or outcomes would induce stronger motivational impact (indicated by a larger P3) and emotional feelings (indicated by a larger LPC) of incentive stimuli among high sensation seeking participants.

\section{Methods}

\section{Participants}

Advertisements for experimental participants placed in local newspapers and on flyers distributed throughout the local community directed volunteers to a website, where study information was provided, and brief health and demographic eligibility was requested. At this website, individuals completed a Likert-scale variation (item scores of 0 to 4 ) of the 19item version of the Impulsive Sensation Seeking (ImpSS) Scale from the ZuckermanKuhlman Personality Questionnaire (ZKPQ) (Hojat \& Zuckerman, 2008; Whiteside \& Lynam, 2003). Excellent reliability and validity of this scale has been established (McDaniel \& Mahan, 2008). 4 of the 19 items are specific to the impulsivity dimension of disinhibition, 11 are specific to the impulsivity dimension of sensation seeking, and 4 contribute to both dimensions (Lynam, personal communication). Using gender-based median splits on the 4 disinhibition and 11 sensation-seeking items [disinhibition: high scores $\geq 10$ for males and females (i.e., no gender differences in median scores on these 4 items); sensation seeking: high scores $\geq 24$ for males and $\geq 23$ for females], individuals were characterized as high and low on each of these impulsivity dimensions and were assigned to one of four groups accordingly (see Group Demographics in the Results section). The functional validity of distinct disinhibition and sensation seeking effects have been confirmed in previous studies on substance use, alcohol dependence, and pathological gambling (Campanella et al., 2016; Fischer \& Smith, 2008; Harvanko et al., 2016; Joseph et al., 2015; Shin, Hong, \& Jeon, 2012).

Individuals attended an initial informational session, and after providing informed consent in accord with the University of Kentucky Medical Institutional Review Board, completed medical and psychological questionnaires, including locally-developed health and personal history questionnaires, a 17-item drug use questionnaire derived from the Addiction Severity Index (McLellan et al., 1992), the Michigan Alcoholism Screening Test (Selzer, Vinokur, \& van Rooijen, 1975), the Sensation-Seeking Scale (Form V; Zuckerman, Eysenck, \& Eysenck, 1978), and the computerized Edinburgh Handedness Inventory (Oldfield, 1971). Participants also completed an eye exam using the MIS Pocket Vision Guide. Pregnancy and drug use (see Table 1) were assessed via breath (Alcohol Sensor III, Intoximeters, Inc.; piCO Carbon Monoxide Monitor, Bedfont Scientific) and urinalysis (Integrated E-Z Split Key ${ }^{\circledR}$ Cup II, Acon Laboratories, San Diego, CA; hCG Assay, Rapid Detect, Inc., Poteau, OK).

Inclusion criteria included good health and right handedness. Exclusion criteria consisted of (1) any major medical conditions, including neurological (e.g., stroke or seizures), psychiatric (e.g., depression, schizophrenia, panic disorder), and learning (e.g., dyslexia, dyspraxia) disorders, (2) prior closed head injury or concussion, (3) the presence of metal in or on the body, (4) poor vision that could not be corrected, (5) current use of medications 
affecting the central nervous system, (6) a history of substance abuse, (7) daily use of nicotine, and (8) pregnancy.

\section{Experimental Procedure}

Participants were recruited in order to examine the independent and interactive effects of disinhibition and sensation seeking on MID task performance and associated electrophysiological activation. Each participant completed two sessions, the first involving functional magnetic resonance imaging (fMRI) and the second involving electrophysiological recording. Session order was counterbalanced within group and gender. Multiple tasks were completed during each session. Due to technical problems, data from six participants were excluded from both the fMRI and ERP data analysis. Consequently, data from 86 participants were included in the final sample. Absence of drug use was verified by urinalysis testing prior to both sessions.

\section{Monetary Incentive Delay (MID) Task Design}

Figure 1 illustrates the experimental procedure of an exemplar trial. At the start of each trial, the incentive cue was presented for $1200 \mathrm{~ms}$. A crosshair was then displayed for a variable interval (1200-2500 ms), followed by presentation of the target screen (white square presented for 130-360 ms). Participants were instructed to press the space bar on the keyboard as soon as the target screen appeared. Target duration began at $250 \mathrm{~ms}$. If participants' overall response accuracy level was higher than $66 \%$ and also made a correct response in the current trial, then target duration would be shorted by $10 \%$ in the next trial; meanwhile, if accuracy level was lower than $66 \%$ and participants made an incorrect response in the current trial, then target duration would increase by $10 \%$ in the next trial. The crosshair was then displayed again until the cumulative duration reached $1000 \mathrm{~ms}$, followed by presentation of the trial outcome screen $(700 \mathrm{~ms})$. After a blank presentation lasting for $300 \mathrm{~ms}$, the screen 'next trial' $(2000 \mathrm{~ms})$ indicated that the following trial was about to begin. Stimuli were presented with E-Prime 1.1 software (Psychology Software Tools, Inc., Pittsburgh, PA).

The MID task consisted of 180 trials of successive incentive cue, target and outcome screen presentations (Bjork, Knutson, et al., 2004; Bjork et al., 2008). Five distinct trial incentive conditions were presented in random order; the number of trials was equal across conditions. Incentive condition was signaled by the cue screen: two reinforcement trial conditions $(+1.20$ and +0.20 cues presented in blue font $)$, two avoidance trial conditions $(-1.20$ and -0.20 cues presented in red font), and one neutral trial condition $(+0.00$ denoted in gray font). In light of the study of Samanez-Larkin et al. (2007), literal symbolic cues (i.e., writing the incentive information of the current trial in Arabic numerals) were applied to replace the traditionally used abstract symbolic cues. On reinforcement trials, if the participant responded within the time window of the target screen, they would win $\$ 1.20$ or $\$ 0.20$. Conversely, on avoidance trials, if the participant responded within the time window of target screen, they would avoid losing $\$ 1.20$ or $\$ 0.20$. During neutral cue trials, no monetary consequences were associated with performance. 
The 180 trials were presented in four blocks of 45 trials, with each block separated by a short rest period. Participants were notified of their cumulative earnings at the end of each block. The lower limit for total earnings did not fall below $\$ 0$, that is, the participant did not owe money in any case. The actual earning varied based on task performance.

\section{Psychophysiological recording and data analysis}

EEGs were recorded from 64 sites using $\mathrm{Ag} / \mathrm{AgCl}$ electrodes embedded in an elastic cap (NeuroScan, Inc., Herndon, VA) at locations designed to cover the scalp. Two additional channels were used for monitoring horizontal and vertical eye movements. An electrode placed between $\mathrm{Cz}$ and $\mathrm{CPz}$ served as a reference. ERP responses were later re-referenced offline to the average of the left and right mastoid potentials. All inter-electrode impedance was maintained at $<5 \mathrm{k} \Omega$. EEG and EOG signals were amplified with a $0.01-100 \mathrm{~Hz}$ online band-pass filter and continuously sampled at $500 \mathrm{~Hz} / \mathrm{channel}$.

During the offline analysis, ocular artifacts were removed from the EEG signal using a regression procedure implemented with Neuroscan software (Semlitsch, Anderer, Schuster, \& Presslich, 1986). The EEG data were then digital filtered (zero phase shift) with a bandpass of $0.05-40 \mathrm{~Hz}$ and were segmented into epochs time-locked to the onset of stimulus presentation. Epochs were then averaged separately for each participant and each condition. Each averaging epoch lasted for $900 \mathrm{~ms}$ with an additional $100 \mathrm{~ms}$ recorded prior to stimulus onset to establish a baseline reference. Any trial in which maximum EEG voltage exceeded a threshold of $\pm 100 \mu \mathrm{V}$ during the recording epoch was excluded from further analysis. After data preprocessing, the surviving trials were determined as artifactfree (-1.2: $95.7 \% ;-0.12$ : 95.4\%; 0: 95.7\%; +0.12: 95.5\%; +1.2: 95.0\%).

As described in the Introduction section, three ERP components (FRN, P3, and LPC) of the $900 \mathrm{~ms}$ epochs elicited by both the cue and outcome screens were examined. The time window (determined by visual detection on grand-averaged waveforms) for data analysis of each component (mean amplitude measurement) was: FRN, 200-300 ms post screen presentation; $\mathrm{P} 3,300-450 \mathrm{~ms}$ post screen; $\mathrm{LPC}, 450-850 \mathrm{~ms}$ post screen.

Please note that, although the FRN is traditionally associated with outcome feedback presentation, recent studies suggest that stimulus cues which predict outcomes evoke an FRN as well (e.g., Dunning \& Hajcak, 2007; Liao, Gramann, Feng, Deak, \& Li, 2011; for a review, see Walsh \& Anderson, 2012). Therefore, the second prominent negative peak in the averaged ERP waveform following cue presentation is also labeled as the FRN, which shared the same time window for analysis with the outcome-related FRN.

\section{Statistical Analysis}

Response accuracy was calculated by dividing the number of correct trials by the total number of trials. Here, 'correct' was defined as a behavioral response within target duration in a given trial. Response times were defined as the time interval from target onset to button press. The performance data (response accuracy and reaction time) were analyzed using three-way Incentive (five levels: $-1.2,-0.2,0,+0.2,+1.2) \times$ Disinhibition (high vs. low) $\times$ Sensation Seeking (high vs. low) analysis of variance (ANOVA) tests, with the Disinhibition and Sensation Seeking groupings as between-subject factors. 
Electrophysiological data following cue screen presentation were analyzed by first determining the electrode location of maximal signal across the midline ( $\mathrm{Fz}, \mathrm{FCz}, \mathrm{Cz}, \mathrm{CPz}$, $\mathrm{Pz}, \mathrm{POz}$, and $\mathrm{Oz}$ ), and then calculating the mean amplitude of this electrode and eight adjacent electrodes (Gu et al., 2011). See Figure 2 for the selection of electrodes. As pointed out by Luck and Gaspelin (2017), collapsing the data across nearby electrode sites helps simplify the structure of data analysis and increase the signal-to-noise ratio.

The results were entered into three-way Incentive $\times$ Disinhibition $\times$ Sensation Seeking ANOVA tests. The same method was applied to the analysis of electrophysiological data following outcome screen presentation, except that correctness of trial outcome (correct vs. incorrect) was added as the fourth factor in ANOVA tests.

For all analyses, the significance level was set at 0.05 . Greenhouse-Geisser corrections were used when appropriate. Post-hoc testing of significant main effects was conducted using the least significant difference (LSD) method. Significant interactions were analyzed using simple-effects models. Partial eta-squared $\left(\eta_{\mathrm{p}}^{2}\right)$ values were provided to demonstrate effect size where appropriate, such that 0.05 represents a small effect, 0.10 represents a medium effect, and 0.20 represents a large effect (J. Cohen, 1973). Statistical analysis was performed using SPSS 15.0 (SPSS, Inc., Chicago, IL). Only significant effects are reported hereafter.

\section{Results}

\section{Group Demographics}

The validity of our grouping was confirmed; the four groups differed significantly on the two dimensions of the ImpSS from the ZKPQ, as well as on total score and on the disinhibition, experience seeking, and thrill and adventure seeking subscales of the Sensation Seeking Scale (Form V), but not in gender, age, or substance use (alcohol, tobacco, etc. See Table 1 for details).

\section{MID Task Performance}

Response Accuracy (ACC)-The main effect of Incentive was significant $(F(4,328)=$ $26.500, p<.001, \eta_{\mathrm{p}}^{2}=.247$ ). Post-hoc analyses indicated significant differences in accuracy across all trial conditions; accuracy was lowest during neutral incentive trials, and increased as a function of incentive for the reinforcement trials, but not the avoidance trials (see Table

2). The main effect of Disinhibition was significant $\left(F(1,82)=7.782, p=.007, \eta_{\mathrm{p}}^{2}=.088\right)$, with response accuracy among low disinhibition participants (65.6\%) being higher than high disinhibition participants (64.7\%). The main effect of Sensation Seeking was also significant $\left(F(1,82)=7.938, p=.006, \eta_{\mathrm{p}}^{2}=.089\right)$, with response accuracy for low sensation-seeking participants $(65.6 \%)$ being higher than high sensation-seeking participants $(64.7 \%)$.

Response Time (RT)-The main effect of incentive was significant $(F(4,328)=24.932$, $\left.p<.001, \eta_{\mathrm{p}}^{2}=.235\right)$. Post-hoc analysis revealed significant differences in RT across all trial conditions, except for the comparison between low reinforcement (' 0.12 ') and low 
avoidance ('-0.12') trials; RT was longest during neutral incentive trials, and decreased as a function of incentive for the reinforcement trials, but not the avoidance trials (see Table 2).

\section{ERP Response to Incentive Cues}

FRN component-The FRN was largest at the frontal-central area of the scalp - electrode position $\mathrm{FCz}(3.75 \mu \mathrm{V})$. Accordingly, the data at this electrode and eight adjacent electrodes (F1, Fz, F2, FC1, FC2, C1, Cz, and C2) were chosen for analysis. The arithmetic averages of the mean amplitudes of these electrodes were entered into the ANOVA test, as suggested by Luck and Gaspelin (2017). The main effect of Incentive was significant $(F(4,328)=5.664, p$ $\left.=.002, \eta_{\mathrm{p}}^{2}=.065\right)$; the FRN was largest during neutral incentive trials, and decreased as a function of incentive for both the reinforcement and avoidance trials (see Table 2; see also supplementary material).

P3 component-The P3 was largest at the parietal-occipital area of the scalp - electrode position $\mathrm{POz}(7.27 \mu \mathrm{V})$. Accordingly, the mean amplitudes of this electrode and eight adjacent electrodes (P1, Pz, P2, PO3, PO4, O1, Oz, and O2) were entered into the ANOVA test. The main effect of Incentive was significant $\left(F(4,328)=17.341, p<.001, \eta_{\mathrm{p}}^{2}=.175\right)$; the P3 was largest for high reinforcement ('+1.2') trials, and smallest for neutral incentive trials. In general, the P3 amplitude increased as a function of incentive for both the reinforcement and avoidance trials (see Table 2; see also supplementary material).

LPC component-The LPC was largest at the parietal area of the scalp - electrode position $\mathrm{Pz}(3.56 \mu \mathrm{V})$. Accordingly, the mean amplitudes of this electrode and eight adjacent electrodes (CP1, CPz, CP2, P1, P2, PO3, POz, and PO4) were entered into the ANOVA test.

The main effect of Incentive was significant $\left(F(4,328)=31.155, p<.001, \eta_{\mathrm{p}}^{2}=.275\right)$; the LPC was largest during high reinforcement trials. The LPC increased as a function of incentive for the reinforcement trials, but not the avoidance trials (see Table 2). The Incentive $\times$ Disinhibition interaction was significant $\left(F(4,328)=2.575, p=.049, \eta_{\mathrm{p}}^{2}=.030\right)$ : in high disinhibition participants, the LPC during high reinforcement trials was significantly larger than all the other conditions ( $p s \leq .005$ ); in low disinhibition participants, the LPC during high reinforcement trials was larger than all the other conditions ( $p s \leq .001)$ except high avoidance trials $(p=.072)$ (see Figure 3 ).

\section{ERP Responses to Outcome Presentation}

FRN component-The FRN was largest at the frontal area of the scalp - electrode position $\mathrm{Fz}(7.13 \mu \mathrm{V})$. Accordingly, the mean amplitudes of this electrode and eight adjacent electrodes (FP1, FPz, FP2, F1, F2, FC1, FCz, and FC2) were entered into the ANOVA test.

A main effect of Incentive was observed $\left(F(4,312)=14.192, p<.001, \eta_{\mathrm{p}}^{2}=.154\right)$; the FRN was largest during neutral incentive trials, and decreased as a function of incentive for both the reinforcement and avoidance trials (see Table 2). A three-way Incentive $\times$ Correctness $\times$ Disinhibition interaction was observed $\left(F(4,312)=4.452, p=.002, \eta_{\mathrm{p}}^{2}=.054\right)$. Simpleeffects analyses indicated a significant Incentive $\times$ Correctness interaction for high disinhibition $\left(F(4,152)=4.698, p=.002, \eta_{\mathrm{p}}^{2}=.110\right)$ but not low disinhibition participants $(p$ 
$>$.05), with group differences most apparent during neutral incentive trials (see also supplementary material). As illustrated in Figure 4, during neutral incentive trials, correct outcomes engendered a greater FRN than incorrect outcomes among high disinhibition participants $\left(p=.024, \eta_{\mathrm{p}}^{2}=.127\right)$, but the effect of correctness was not significant in low disinhibition groups $(p=.231)$.

P3 component-The P3 was largest at the central area of the scalp - electrode position $\mathrm{Cz}$ $(11.93 \mu \mathrm{V})$. Accordingly, the mean amplitudes of this electrode and eight adjacent electrodes (FC1, FCz, FC2, C1, C2, CP1, CPz, and CP2) were entered into the ANOVA test. A main effect of Incentive was observed $\left(F(4,320)=22.884, p<.001, \eta_{\mathrm{p}}^{2}=.222\right)$; the P3 was smallest during neutral incentive trials, and increased as a function of incentive for both the reinforcement and avoidance trials (see Table 2). A significant Disinhibition $\times$ Sensation Seeking interaction was observed $\left(F(1,80)=4.782, p=.032, \eta_{\mathrm{p}}^{2}=.056\right)$. Specifically, the effect of sensation seeking on P3 amplitudes was significant $(F(1,42)=4.213, p=.046$,

$\left.\eta_{\mathrm{p}}^{2}=.091\right)$ with low disinhibition levels, such that high sensation-seeking participants showed a larger P3 elicited by outcome feedback than their low sensation-seeking counterparts; in contrast, this effect was not significant $(F(1,38)=1.009, p=.322)$ with high disinhibition levels (see Figure 5).

LPC component-The LPC was largest at the central area of the scalp - electrode position $\mathrm{Cz}(4.93 \mu \mathrm{V})$. Accordingly, the mean amplitudes of this electrode and eight adjacent electrodes (FC1, FCz, FC2, C1, C2, CP1, CPz, and CP2) were entered into the ANOVA test. A main effect of Incentive was observed $\left(F(4,320)=5.191, p=.002, \eta_{\mathrm{p}}^{2}=.061\right)$; the LPC was larger in high avoidance trials than the other conditions ( $p s \leq .012)$ except high reinforcement trials $(p=.702)$ (see Table 2$)$.

\section{Discussion}

This study investigates the influence of disinhibition and sensation seeking dimensions of impulsive personality on behavioral performance and brain activation during MID task performance as a function of monetary incentive conditions. Impulsive personality dimensions were associated with individual differences in response accuracy and electrophysiological signals. Further, the influences of disinhibition and sensation seeking on the ERPs showed different patterns, reflecting distinct effects of the two dimensions of impulsivity. In our opinion, the current findings indicate a possibility to dissociate the two dimensions on the neural level.

We expected that individual difference in disinhibition would be related to worse MID task performance. In reality, the main effects of both disinhibition and sensation seeking were observed, such that low disinhibition groups exhibited more accurate performance than their high disinhibition counterparts, and the same was true for sensation seeking. The behavioral results reveal that the cognitive functions associated with accurate responses in the MID task are weakened among individuals high in either disinhibition or sensation-seeking levels. 
This finding is in line with previous observations that impulsivity dampens behavioral performance in cognitive tasks (Brown et al., 2012; Ersche et al., 2010; Kim \& Lee, 2011).

Although the MID task performance did not distinguish between the two impulsivity dimensions, the ERP results revealed independent influences of disinhibition and sensation seeking on electrophysiological signals. These influences were evidenced on the LPC elicited by incentive cue presentation and on the FRN and P3 elicited by outcome screens. First, the LPC in response to incentive cues showed an interaction between incentive levels and disinhibition: in high disinhibition groups, the LPC elicited by high reinforcement cues was larger than the other four types of cues; in low disinhibition groups, however, the LPC was not significantly different between high reinforcement and high avoidance cues. Based on this finding, we suggest that for high disinhibition people, the emotional influence of high reinforcement cues is predominant. In contrast, high reinforcement and high avoidance cues produce comparable emotional influence on low disinhibition people.

The FRN elicited by outcome presentation was insensitive to the correctness factor, which does not support the traditional 'favorableness' hypothesis of the FRN (Hajcak, Moser, Holroyd, \& Simons, 2006; Nieuwenhuis et al., 2004; see also the Introduction section). Instead, we use the PRO model to interpret the current FRN findings. This component reached its peak in the neutral incentive condition, and declined as a function of incentive for both reinforcement and avoidance trials. Based on the PRO model, we suggest that in high incentive conditions, participants were more engaged in the task, therefore their outcome prediction were more accurate. In contrast, during neutral incentive trials, participants provided more stochastic behavioral responses, thus they were more likely to be surprised by outcome feedback (i.e., unexpected wins and losses) and showed a larger FRN response in general. Our interpretation on the FRN is consistent with a recent study from Pfabigan et al. (2015) which also applied the MID task.

Most importantly, group differences across trial conditions between high and low disinhibition participants were also observed with the FRN. Specifically, the FRN amplitude varied as a function of disinhibition but not sensation seeking, such that correct outcome elicited a larger FRN than incorrect outcome in high disinhibition groups during trials with no incentives. In contrast, the FRN pattern among low disinhibition participants did not vary as a function of incentive conditions. To our knowledge, this study is among the first ones to report that correct feedback elicits a larger FRN than incorrect feedback in certain groups of people (see also Cao, Gu, Bi, Zhu, \& Wu, 2015), although it has long been acknowledged that the FRN amplitude is sensitive to individual difference in personality constructs (Proudfit, 2015; San Martín, 2012). According to the PRO model, this surprising finding indicates that in the neutral incentive condition, correct outcomes were more unexpected than incorrect ones for high disinhibition participants. In our opinion, high disinhibition participants are more likely to be driven by extrinsic rewards; they had paid less cognitive efforts to do the task under zero-value reward, thus they did not expect to perform correctly. Consequently, correct outcomes violated their expectation more strongly in this condition (see also Pfabigan et al., 2015). In contrast, low disinhibition participants expected to do the right thing regardless of the incentive amount, indicating the effect of intrinsic motivation (i.e., the inherent tendency to explore and to learn; see Ryan \& Deci, 2000). This 
interpretation can help explain why disinhibition level accounts for variability in maladaptive decision-making (Crone, Vendel, \& van der Molen, 2003; Fischer \& Smith, 2004).

The major neural contributor of the FRN is widely suggested to be the anterior cingulate cortex (ACC) (M. X. Cohen, Wilmes, \& van de Vijver, 2011), which is structurally and functionally associated with levels of disinhibition (Kerr et al., 2015; Matsuo et al., 2009). Accordingly, we suggest that the FRN data of this study also indicate the relationship between disinhibition and ACC functioning, which supports the viewpoint of linking different dimensions of impulsivity with separate brain circuits. Specifically, disinhibition and sensation seeking are related to abnormal activity in prefrontal "executive" system including the ACC and dopaminergic "impulsive" system, respectively (Dawe et al., 2004; Gullo et al., 2014). Hypoactive ACC results in impaired top-down behavioral control (Lyvers, Duff, Basch, \& Edwards, 2012), which may underlie the low response accuracy of high disinhibition participants.

Finally, as predicted, high sensation seeking levels were related to a larger P3 elicited by outcomes, but this relationship was observed only in low disinhibition groups. Consistent with the current study, a positive correlation between sensation seeking and P3 amplitude has been reported in a novelty detection paradigm (Zheng et al., 2010). We extend previous findings by revealing that the effect of sensation seeking interacts with disinhibition, which should not be surprising regarding the shared biological connections of the two dimensions (McDaniel \& Mahan, 2008). In our opinion, the P3 result indicates stronger motivations of high sensation seeking individuals when engaging in reward-related cognitive tasks, which is support by our brain-imaging discovery that high sensation seekers show stronger activation in brain regions associated with motivational salience (Joseph et al., 2009). We admit it is unclear why the effect of sensation seeking diminished when disinhibition levels were higher, but it might be related to the observation that the role of disinhibition in stimulant dependence outweighs that of sensation seeking (Dawe et al., 2004), the theoretical significance of which deserves future investigation. In addition, the key regions in the dopaminergic reward processing system such as the ventral striatum, which play important roles in the neural basis of MID task performance (Joseph et al., 2015; Knutson et al., 2000), might have also contributed to the P3 findings (Pfabigan et al., 2014).

In sum, the importance of impulsivity dimensions manifested in both behavioral performance and brain electric signals in the MID task. While disinhibition and sensation seeking showed similar effects on response accuracy, the ERP results indicate a potential way to dissociate them. Based on the ERPs, we suggest that high disinhibition scores are associated with a more pessimistic outcome expectation when behavioral performance was not rewarded (indexed by the FRN amplitude), possibly because high disinhibition individuals have allocated less cognitive efforts on the task in this condition. Meanwhile, high disinhibition individuals are also more likely to be emotionally affected by high reinforcement cues than other conditions (indexed by the LPC amplitude). Finally, high sensation seeking scores are associated with stronger motivational significance of outcome feedback (indexed by the P3 amplitude), but this relationship is restricted by disinhibition levels, which may represent an interaction between the two dimensions. Our findings have 
the potential to explain why disinhibition and sensation seeking are involved in different periods of chronic drug abuse (Dawe et al., 2004). Specifically, disinhibition mainly affects the processing of drug cues and associated behavioral responses, while sensation seeking modulates drug-related experience. The current study also highlights the necessarily of considering different impulsivity dimensions and their relationship with reward presence/ absence (Cservenka, Herting, Seghete, Hudson, \& Nagel, 2012), but we should avoid the risk of oversimplifying the distinction between two dimensions regarding that neuropsychological processes underlying each dimension do not operate in isolation (Gullo et al., 2014).

\section{Supplementary Material}

Refer to Web version on PubMed Central for supplementary material.

\section{Acknowledgments}

This study is supported by the National Institutes of Drug Abuse (NIDA P50DA005312), the National Centers for Research Resources and Advancing Translational Sciences (UL1RR033173, UL1TR000117), the National Natural Science Foundation of China (31571124, 31671173), and the State Scholarship Fund (201504910062). The content is solely the responsibility of the authors and does not necessarily represent the official views of the National Institutes of Health. The authors sincerely thank Chase Kluemper and Christine Corbly for their participation in data collection.

\section{References}

Amodio DM, Bartholow BD, Ito TA. Tracking the dynamics of the social brain: ERP approaches for social cognitive and affective neuroscience. Social Cognitive \& Affective Neuroscience. 2014; 9(3): 385-393. DOI: 10.1093/scan/nst177 [PubMed: 24319116]

Balconi M, Crivelli D. FRN and P300 ERP effect modulation in response to feedback sensitivity: The contribution of punishment-reward system (BIS/BAS) and Behaviour Identification of action. Neuroscience Research. 2010; 66(2):162-172. DOI: 10.1016/j.neures.2009.10.011 [PubMed: 19895858]

Balodis IM, Potenza MN. Anticipatory reward processing in addicted populations: A focus on the monetary incentive delay task. Biological Psychiatry. 2014; 77(5):434-444. DOI: 10.1016/ j.biopsych.2014.08.020 [PubMed: 25481621]

Bari A, Robbins TW. Inhibition and impulsivity: Behavioral and neural basis of response control. Progress in Neurobiology. 2013; 108:44-79. DOI: 10.1016/j.pneurobio.2013.06.005 [PubMed: 23856628]

Bjork JM, Hommer DW, Grant SJ, Danube C. Impulsivity in abstinent alcohol-dependent patients: Relation to control subjects and type 1-/type 2-like traits. Alcohol. 2004; 34(2-3):133-150. DOI: 10.1016/j.alcohol.2004.06.012 [PubMed: 15902907]

Bjork JM, Knutson B, Fong GW, Caggiano DM, Bennett SM, Hommer DW. Incentive-elicited brain activation in adolescents: Similarities and differences from young adults. Journal of Neuroscience. 2004; 24(8):1793-1802. DOI: 10.1523/JNEUROSCI.4862-03.2004 [PubMed: 14985419]

Bjork JM, Knutson B, Hommer DW. Incentive-elicited striatal activation in adolescent children of alcoholics. Addiction. 2008; 103(8):1308-1319. DOI: 10.1111/j.1360-0443.2008.02250.x [PubMed: 18851716]

Brown MR, Lebel RM, Dolcos F, Wilman AH, Silverstone PH, Pazderka H, ... Dursun SM. Effects of emotional context on impulse control. Neuroimage. 2012; 63(1):434-446. DOI: 10.1016/ j.neuroimage.2012.06.056 [PubMed: 22781161]

Broyd SJ, Richards HJ, Helps SK, Chronaki G, Bamford S, Sonuga-Barke EJ. An electrophysiological monetary incentive delay (e-MID) task: A way to decompose the different components of neural 
response to positive and negative monetary reinforcement. Journal of Neuroscience Methods. 2012; 209(1):40-49. DOI: 10.1016/j.jneumeth.2012.05.015 [PubMed: 22659003]

Campanella S, Absil J, Carbia Sinde C, Schroder E, Peigneux P, Bourguignon M, ... De Tiege X. Neural correlates of correct and failed response inhibition in heavy versus light social drinkers: An fMRI study during a go/no-go task by healthy participants. Brain Imaging and Behavior. 2016; published online. doi: 10.1007/s11682-016-9654-y

Cao J, Gu R, Bi X, Zhu X, Wu H. Unexpected acceptance? Patients with social anxiety disorder manifest their social expectancy in ERPs during social feedback processing. Frontiers in Psychology. 2015; 6:1745.doi: 10.3389/fpsyg.2015.01745 [PubMed: 26635659]

Cohen J. Eta-squared and partial eta-squared in xed factor ANOVA designs. Educational and Psychological Measurement. 1973; 33(1):107-112. DOI: 10.1177/001316447303300111

Cohen MX, Wilmes K, van de Vijver I. Cortical electrophysiological network dynamics of feedback learning. Trends in Cognitive Sciences. 2011; 15(12):558-566. DOI: 10.1016/j.tics.2011.10.004 [PubMed: 22078930]

Crone EA, Vendel I, van der Molen MW. Decision-making in disinhibited adolescents and adults: Insensitivity to future consequences or driven by immediate reward? Personality and Individual Differences. 2003; 35(7):1625-1641. DOI: 10.1016/S0191-8869(02)00386-0

Cservenka A, Herting MM, Seghete KL, Hudson KA, Nagel BJ. High and low sensation seeking adolescents show distinct patterns of brain activity during reward processing. Neuroimage. 2012; 66(2):184-193. DOI: 10.1016/j.neuroimage.2012.11.003 [PubMed: 23142276]

Dalley JW, Everitt BJ, Robbins TW. Impulsivity, compulsivity, and top-down cognitive control. Neuron. 2011; 69(4):680-694. DOI: 10.1016/j.neuron.2011.01.020 [PubMed: 21338879]

Dawe S, Gullo MJ, Loxton NJ. Reward drive and rash impulsiveness as dimensions of impulsivity: Implications for substance misuse. Addictive Behaviors. 2004; 29(7):1389-1405. DOI: 10.1016/ j.addbeh.2004.06.004 [PubMed: 15345272]

De Bruijn, ER., Mars, RB., Hulstijn, W. It wasn't me... or was it? How false feedback affects performance. In: Ullsperger, M., Falkenstein, M., editors. Errors, conflicts, and the brain: Current opinions on performance monitoring. Leipzig: Max Planck Institute for Human Cognitive and Brain Sciences; 2004. p. 118-124.

Diekhof EK, Nerenberg L, Falkai P, Dechent P, Baudewig J, Gruber O. Impulsive personality and the ability to resist immediate reward: An fMRI study examining interindividual differences in the neural mechanisms underlying self-control. Human Brain Mapping. 2012; 33(12):2768-2784. DOI: 10.1002/hbm.21398 [PubMed: 21938756]

Dunning JP, Hajcak G. Error-related negativities elicited by monetary loss and cues that predict loss. Neuroreport. 2007; 18(17):1875-1878. DOI: 10.1097/WNR.0b013e3282f0d50b [PubMed: 18090330]

Ersche KD, Turton AJ, Pradhan S, Bullmore ET, Robbins TW. Drug addiction endophenotypes: Impulsive versus sensation-seeking personality traits. Biological Psychiatry. 2010; 68(8):770-773. DOI: 10.1016/j.biopsych.2010.06.015 [PubMed: 20678754]

Ferdinand NK, Mecklinger A, Kray J, Gehring WJ. The processing of unexpected positive response outcomes in the mediofrontal cortex. The Journal of Neuroscience. 2012; 32(35):12087-12092. DOI: 10.1523/JNEUROSCI.1410-12.2012 [PubMed: 22933792]

Fiorillo CD, Tobler PN, Schultz W. Discrete coding of reward probability and uncertainty by dopamine neurons. Science. 2003; 299(5614):1898-1902. DOI: 10.1126/science.1077349 [PubMed: 12649484]

Fischer S, Smith GT. Deliberation affects risk taking beyond sensation seeking. Personality and Individual Differences. 2004; 36(3):527-537. DOI: 10.1016/S0191-8869(03)00112-0

Fischer S, Smith GT. Binge eating, problem drinking, and pathological gambling: Linking behavior to shared traits and social learning. Personality and Individual Differences. 2008; 44(4):789-800. DOI: $10.1016 /$ j.paid.2007.10.008

Flores A, Munte TF, Donamayor N. Event-related EEG responses to anticipation and delivery of monetary and social reward. Biological Psychology. 2015; 109:10-19. DOI: 10.1016/j.biopsycho. 2015.04.005 [PubMed: 25910956] 
Garofalo S, Maier ME, di Pellegrino G. Mediofrontal negativity signals unexpected omission of aversive events. Scientific Reports. 2014; 4:4816.doi: 10.1038/srep04816 [PubMed: 25045961]

Gu R, Lei Z, Broster L, Wu T, Jiang Y, Luo YJ. Beyond valence and magnitude: A flexible evaluative coding system in the brain. Neuropsychologia. 2011; 49(14):3891-3897. DOI: 10.1016/ j.neuropsychologia.2011.10.006 [PubMed: 22019775]

Gullo MJ, Loxton NJ, Dawe S. Impulsivity: Four ways five factors are not basic to addiction. Addictive behaviors. 2014; 39(11):1547-1556. DOI: 10.1016/j.addbeh.2014.01.002 [PubMed: 24576666]

Hajcak G, Dunning JP, Foti D. Motivated and controlled attention to emotion: Time-course of the late positive potential. Clinical Neurophysiology. 2009; 120(3):505-510. DOI: 10.1016/j.clinph. 2008.11.028 [PubMed: 19157974]

Hajcak G, Moser JS, Holroyd CB, Simons RF. The feedback-related negativity reflects the binary evaluation of good versus bad outcomes. Biological Psychology. 2006; 71(2):148-154. DOI: 10.1016/j.biopsycho.2005.04.001 [PubMed: 16005561]

Hajcak G, Olvet DM. The persistence of attention to emotion: Brain potentials during and after picture presentation. Emotion. 2008; 8(2):250-255. DOI: 10.1037/1528-3542.8.2.250 [PubMed: 18410198]

Harvanko A, Martin C, Lile J, Kryscio R, Kelly TH. Individual differences in the reinforcing and subjective effects of d-Amphetamine: Dimensions of impulsivity. Experimental and Clinical Psychopharmacology. 2016; 24(6):436-446. DOI: 10.1037/pha0000095 [PubMed: 27929346]

Hauser TU, Iannaccone R, Stämpfli P, Drechsler R, Brandeis D, Walitza S, Brem S. The feedbackrelated negativity (FRN) revisited: New insights into the localization, meaning and network organization. Neuroimage. 2014; 84:159-168. DOI: 10.1016/j.neuroimage.2013.08.028 [PubMed: 23973408]

Hill EM, Ross LT, Low BS. The role of future unpredictability in human risk-taking. Human Nature-an Interdisciplinary Biosocial Perspective. 1997; 8(4):287-325. DOI: 10.1007/BF02913037

Hojat M, Zuckerman M. Personality and specialty interest in medical students. Medical Teacher. 2008; 30(4):400-406. [PubMed: 18569662]

Holroyd CB, Coles MGH. The neural basis of human error processing: Reinforcement learning, dopamine, and the error-related negativity. Psychological Review. 2002; 109(4):679-709. DOI: 10.1037/0033-295X.109.4.679 [PubMed: 12374324]

Jiang Y, Lianekhammy J, Lawson A, Guo CY, Lynam D, Joseph JE, ... Kelly TH. Brain responses to repeated visual experience among low and high sensation seekers: Role of boredom susceptibility. Psychiatry Research-Neuroimaging. 2009; 173(2):100-106. DOI: 10.1016/j.pscychresns. 2008.09.012

Joseph JE, Liu X, Jiang Y, Lynam D, Kelly TH. Neural correlates of emotional reactivity in sensation seeking. Psychological Science. 2009; 20(2):215-223. DOI: 10.1111/j.1467-9280.2009.02283.x [PubMed: 19222814]

Joseph JE, Zhu X, Corbly CR, DeSantis S, Lee DC, Baik G, ... Kelly TH. Influence of neurobehavioral incentive valence and magnitude on alcohol drinking behavior. Neuroimage. 2015; 104:373-385. DOI: 10.1016/j.neuroimage.2014.09.037 [PubMed: 25261001]

Kamarajan C, Rangaswamy M, Chorlian DB, Manz N, Tang Y, Pandey AK, ... Porjesz B. Theta oscillations during the processing of monetary loss and gain: A perspective on gender and impulsivity. Brain Research. 2008; 1235:45-62. [PubMed: 18616934]

Kelly Robbins G, Martin CA, Fillmore MT, Lane SD, Harrington NG, Rush CR. Individual differences in drug abuse vulnerability: d-Amphetamine and sensation-seeking status. Psychopharmacology. 2006; 189(1):17-25. DOI: 10.1007/s00213-006-0487-z [PubMed: 16972106]

Kerr KL, Avery JA, Barcalow JC, Moseman SE, Bodurka J, Bellgowan PS, Simmons WK. Trait impulsivity is related to ventral ACC and amygdala activity during primary reward anticipation. Social Cognitive \& Affective Neuroscience. 2015; 10(1):36-42. DOI: 10.1093/scan/nsu023 [PubMed: 24526181]

Kim S, Lee D. Prefrontal cortex and impulsive decision making. Biological Psychiatry. 2011; 69(12): 1140-1146. DOI: 10.1016/j.biopsych.2010.07.005 [PubMed: 20728878] 
Knutson B, Adams CM, Fong GW, Hommer D. Anticipation of increasing monetary reward selectively recruits nucleus accumbens. Journal of Neuroscience. 2001; 21(16) art. no.-RC159.

Knutson B, Bhanji JP, Cooney RE, Atlas LY, Gotlib IH. Neural responses to monetary incentives in major depression. Biological Psychiatry. 2008; 63(7):686-692. DOI: 10.1016/j.biopsych. 2007.07.023 [PubMed: 17916330]

Knutson B, Westdorp A, Kaiser E, Hommer D. FMRI visualization of brain activity during a monetary incentive delay task. Neuroimage. 2000; 12(1):20-27. DOI: 10.1006/nimg.2000.0593 [PubMed: 10875899]

Langeslag SJ, van Strien JW. Up-regulation of emotional responses to reward-predicting stimuli: An ERP study. Biological Psychology. 2013; 94(1):228-233. DOI: 10.1016/j.biopsycho.2013.05.021 [PubMed: 23770414]

Liao Y, Gramann K, Feng WF, Deak GO, Li H. This ought to be good: Brain activity accompanying positive and negative expectations and outcomes. Psychophysiology. 2011; 48(10):1412-1419. DOI: 10.1111/j.1469-8986.2011.01205.x [PubMed: 21517899]

Loewenstein GF, Weber EU, Hsee CK, Welch N. Risk as feelings. Psychological Bulletin. 2001; 127(2):267-286. DOI: 10.1037/0033-2909.127.2.267 [PubMed: 11316014]

Luck SJ, Gaspelin N. How to get statistically significant effects in any ERP experiment (and why you shouldn’t). Psychophysiology. 2017; 54(1):146-157. DOI: 10.1111/psyp.12639 [PubMed: 28000253]

Lyvers M, Duff H, Basch V, Edwards MS. Rash impulsiveness and reward sensitivity in relation to risky drinking by university students: potential roles of frontal systems. Addictive Behaviors. 2012; 37(8):940-946. DOI: 10.1016/j.addbeh.2012.03.028 [PubMed: 22521364]

Macleod J, Oakes R, Copello A, Crome L, Egger M, Hickman M, ... Smith GD. Psychological and social sequelae of cannabis and other illicit drug use by young people: A systematic review of longitudinal, general population studies. Lancet. 2004; 363(9421):1579-1588. DOI: 10.1016/ S0140-6736(04)16200-4 [PubMed: 15145631]

Martin LE, Potts GF. Reward sensitivity in impulsivity. Neuroreport. 2004; 15(9):1519-1522. DOI: 10.1097/01.wnr.0000132920.12990.b9 [PubMed: 15194887]

Martin LE, Potts GF. Impulsivity and decision-making: An event related potential investigation. Personality and Individual Differences. 2009; 46(3):303-308. DOI: 10.1016/j.paid.2008.10.019 [PubMed: 20126284]

Martin SB, Covell DJ, Joseph JE, Chebrolu H, Smith CD, Kelly TH, ... Gold BT. Human experience seeking correlates with hippocampus volume: Convergent evidence from manual tracing and voxel-based morphometry. Neuropsychologia. 2007; 45(12):2874-2881. DOI: 10.1016/ j.neuropsychologia.2007.05.009 [PubMed: 17603086]

Marusich JA, Darna M, Charnigo RJ, Dwoskin LP, Bardo MT. A multivariate assessment of individual differences in sensation seeking and impulsivity as predictors of amphetamine self-administration and prefrontal dopamine function in rats. Experimental and Clinical Psychopharmacology. 2011; 19(4):275-284. DOI: 10.1037/a0023897 [PubMed: 21574722]

Matsuo K, Nicoletti M, Nemoto K, Hatch JP, Peluso MA, Nery FG, Soares JC. A voxel-based morphometry study of frontal gray matter correlates of impulsivity. Human Brain Mapping. 2009; 30(4):1188-1195. DOI: 10.1002/hbm.20588 [PubMed: 18465751]

McDaniel SR, Mahan JE. An examination of the ImpSS scale as a valid and reliable alternative to the SSS-V in optimum stimulation level research. Personality and Individual Differences. 2008; 44(7): 1528-1538. DOI: 10.1016/j.paid.2008.01.009

McLellan AT, Kushner H, Metzger D, Peters R, Smith I, Grissom G, ... Argeriou M. The fifth edition of the Addiction Severity Index. Journal of Substance Abuse Treatment. 1992; 9:199-213. [PubMed: 1334156]

Nieuwenhuis S, Aston-Jones G, Cohen JD. Decision making, the P3, and the locus coeruleusnorepinephrine system. Psychological Bulletin. 2005; 131(4):510-532. DOI: 10.1037/0033-2909.131.4.510 [PubMed: 16060800]

Nieuwenhuis S, Holroyd CB, Mol N, Coles MGH. Reinforcement-related brain potentials from medial frontal cortex: Origins and functional significance. Neuroscience \& Biobehavioral Reviews. 2004; 28(4):441-448. DOI: 10.1016/j.neubiorev.2004.05.003 [PubMed: 15289008] 
Novak BK, Novak KD, Lynam DR, Foti D. Individual differences in the time course of reward processing: Stage-specific links with depression and impulsivity. Biological Psychology. 2016; 119:79-90. DOI: 10.1016/j.biopsycho.2016.07.008 [PubMed: 27396750]

Novak KD, Foti D. Teasing apart the anticipatory and consummatory processing of monetary incentives: An event-related potential study of reward dynamics. Psychophysiology. 2015; 52(11): 1470-1482. DOI: 10.1111/psyp.12504 [PubMed: 26223291]

Oldfield RC. Assessment and analysis of handedness - Edinburgh Inventory. Neuropsychologia. 1971; 9(1):97.doi: 10.1016/0028-3932(71)90067-4 [PubMed: 5146491]

Perry JL, Joseph JE, Jiang Y, Zimmerman RS, Kelly TH, Darna M, ... Bardo MT. Prefrontal cortex and drug abuse vulnerability: Translation to prevention and treatment interventions. Brain Research Reviews. 2010; 65(2):124-149. DOI: 10.1016/j.brainresrev.2010.09.001 [PubMed: 20837060]

Pfabigan DM, Seidel EM, Paul K, Grahl A, Sailer U, Lanzenberger R, ... Lamm C. Context-sensitivity of the feedback-related negativity for zero-value feedback outcomes. Biological Psychology. 2015; 104:184-192. DOI: 10.1016/j.biopsycho.2014.12.007 [PubMed: 25541513]

Pfabigan DM, Seidel EM, Sladky R, Hahn A, Paul K, Grahl A, ... Windischberger C. P300 amplitude variation is related to ventral striatum BOLD response during gain and loss anticipation. Neuroimage. 2014; 96:12-21. DOI: 10.1016/j.neuroimage.2014.03.077 [PubMed: 24718288]

Polezzi D, Sartori G, Rumiati R, Vidotto G, Daum I. Brain correlates of risky decision-making. Neuroimage. 2010; 49(2):1886-1894. DOI: 10.1016/j.neuroimage.2009.08.068 [PubMed: 19761850]

Polich J. Updating P300: An integrative theory of P3a and P3b. Clinical Neurophysiology. 2007; 118(10):2128-2148. DOI: 10.1016/j.clinph.2007.04.019 [PubMed: 17573239]

Polich J, Criado JR. Neuropsychology and neuropharmacology of P3a and P3b. International Journal of Psychophysiology. 2006; 60(2):172-185. DOI: 10.1016/j.ijpsycho.2005.12.012 [PubMed: 16510201]

Pornpattananangkul N, Nusslock R. Motivated to win: Relationship between anticipatory and outcome reward-related neural activity. Brain and Cognition. 2015; 100:21-40. DOI: 10.1016/j.bandc. 2015.09.002 [PubMed: 26433773]

Proudfit GH. The reward positivity: From basic research on reward to a biomarker for depression. Psychophysiology. 2015; 52(4):449-459. DOI: 10.1111/psyp.12370 [PubMed: 25327938]

Ryan RM, Deci EL. Self-determination theory and the facilitation of intrinsic motivation, social development, and well-being. American Psychologist. 2000; 55(1):68-78. DOI: 10.1037/0003-066X.55.1.68 [PubMed: 11392867]

Samanez-Larkin GR, Gibbs SEB, Khanna K, Nielsen L, Carstensen LL, Knutson B. Anticipation of monetary gain but not loss in healthy older adults. Nature Neuroscience. 2007; 10(6):787-791. DOI: 10.1038/nn1894 [PubMed: 17468751]

Sambrook TD, Goslin J. Mediofrontal event-related potentials in response to positive, negative and unsigned prediction errors. Neuropsychologia. 2014; 61C:1-10. DOI: 10.1016/j.neuropsychologia. 2014.06.004

San Martín R. Event-related potential studies of outcome processing and feedback-guided learning. Frontiers in Human Neuroscience. 2012; 6:304.doi: 10.3389/fnhum.2012.00304 [PubMed: 23162451]

Schultz W, Tremblay L, Hollerman JR. Reward prediction in primate basal ganglia and frontal cortex. Neuropharmacology. 1998; 37(4-5):421-429. DOI: 10.1016/S0028-3908(98)00071-9 [PubMed: 9704983]

Selzer ML, Vinokur A, van Rooijen L. A self-administered short Michigan alcoholism screening test (SMAST). Journal of Studies on Alcohol. 1975; 36:117-126. [PubMed: 238068]

Semlitsch HV, Anderer P, Schuster P, Presslich O. A solution for reliable and valid reduction of ocular artifacts, applied to the P300 ERP. Psychophysiology. 1986; 23(6):695-703. DOI: 10.1111/j. 1469-8986.1986.tb00696.x [PubMed: 3823345]

Shin SH, Hong HG, Jeon SM. Personality and alcohol use: The role of impulsivity. Addictive Behaviors. 2012; 37(1):102-107. DOI: 10.1016/j.addbeh.2011.09.006 [PubMed: 21955874] 
Talmi D, Atkinson R, El-Deredy W. The feedback-related negativity signals salience prediction errors, not reward prediction errors. Journal of Neuroscience. 2013; 33(19):8264-8269. DOI: 10.1523/ JNEUROSCI.5695-12.2013 [PubMed: 23658166]

Vignapiano A, Mucci A, Ford J, Montefusco V, Plescia GM, Bucci P, Galderisi S. Reward anticipation and trait anhedonia: An electrophysiological investigation in subjects with schizophrenia. Clinical Neurophysiology. 2016; 127(4):2149-2160. DOI: 10.1016/j.clinph.2016.01.006 [PubMed: 26853737]

Walsh MM, Anderson JR. Learning from experience: Event-related potential correlates of reward processing, neural adaptation, and behavioral choice. Neuroscience \& Biobehavioral Reviews. 2012; 36(8):1870-1884. DOI: 10.1016/j.neubiorev.2012.05.008 [PubMed: 22683741]

Whiteside SP, Lynam DR. Understanding the role of impulsivity and externalizing psychopathology in alcohol abuse: Application of the UPPS impulsive behavior scale. Experimental and Clinical Psychopharmacology. 2003; 11(3):210-217. DOI: 10.1037/1064-1297.11.3.210 [PubMed: 12940500]

Zheng Y, Xu J, Jin Y, Sheng W, Ma Y, Zhang X, Shen H. The time course of novelty processing in sensation seeking: An ERP study. International Journal of Psychophysiology. 2010; 76(2):57-63. DOI: 10.1016/j.ijpsycho.2010.02.003 [PubMed: 20171999]

Zuckerman M, Eysenck S, Eysenck HJ. Sensation seeking in England and America - Cross-cultural, age, and sex comparisons. Journal of Consulting and Clinical Psychology. 1978; 46(1):139-149. DOI: 10.1037/0022-006X.46.1.139 [PubMed: 627648] 


\section{Highlights}

- MID task accuracy decreased as a function of two dimensions of impulsivity.

- Impulsivity biased brain responses to reinforcing stimuli at as early as 200 msec.

- Under no incentive, an atypical FRN was seen in people with high disinhibition.

- The P3 was larger in high sensation seeking people when disinhibition was low. 
$100-300 \mathrm{~ms}$

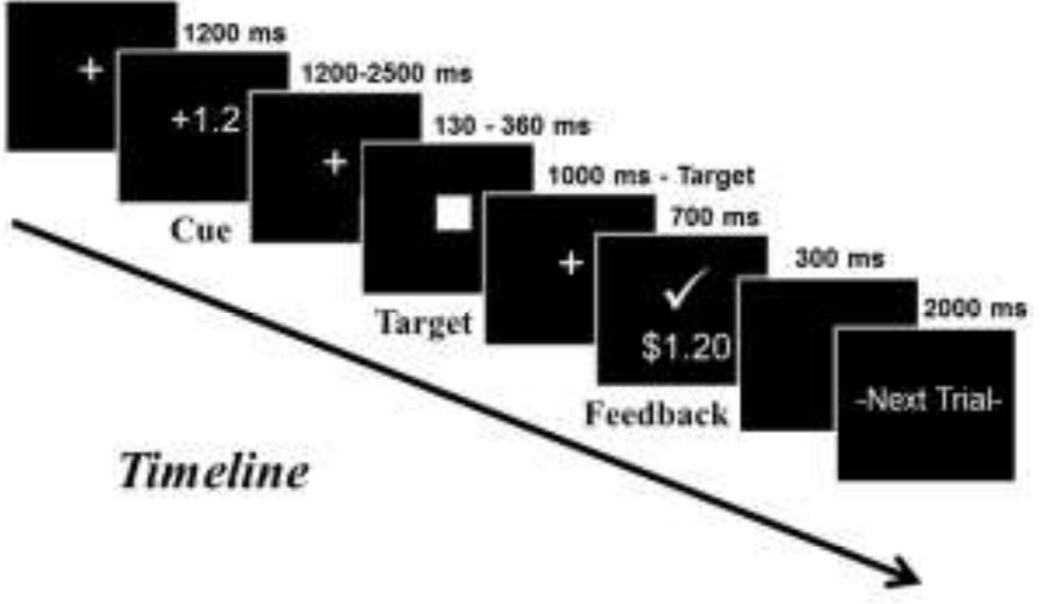

Figure 1.

The sequence of events within a single trial of the MID task. 


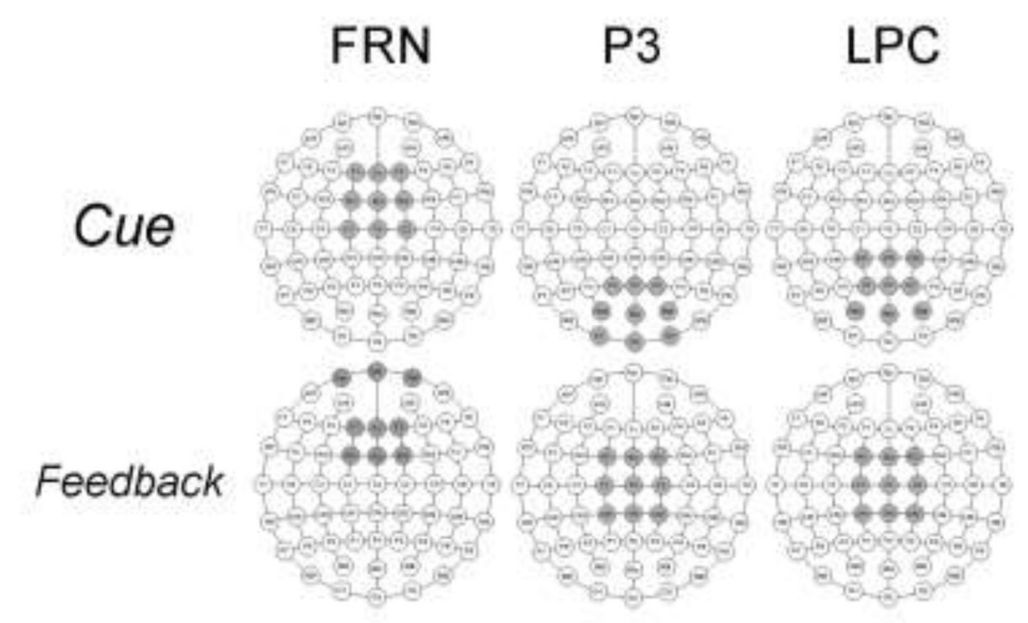

Figure 2.

The electrode locations selected for the analysis of each ERP component. 


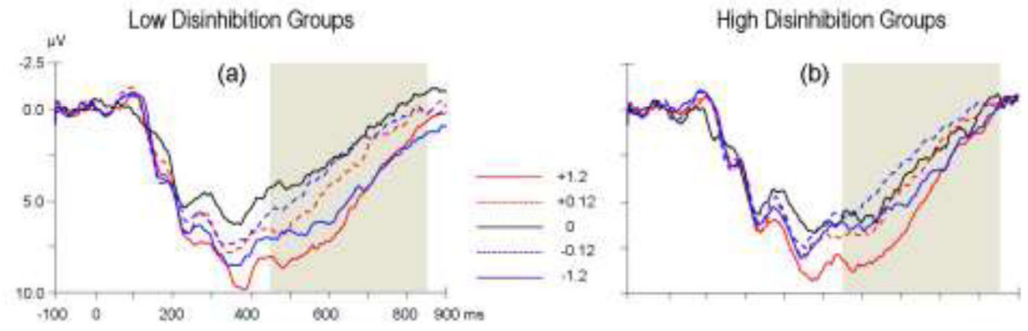

Figure 3. The grand-average ERPs evoked by the cue at the Pz site, where the LPC (following cue presentation) reached its maximum

The gray shaded area indicates the $450-850 \mathrm{~ms}$ time window in which the mean amplitude of LPC was measured. 

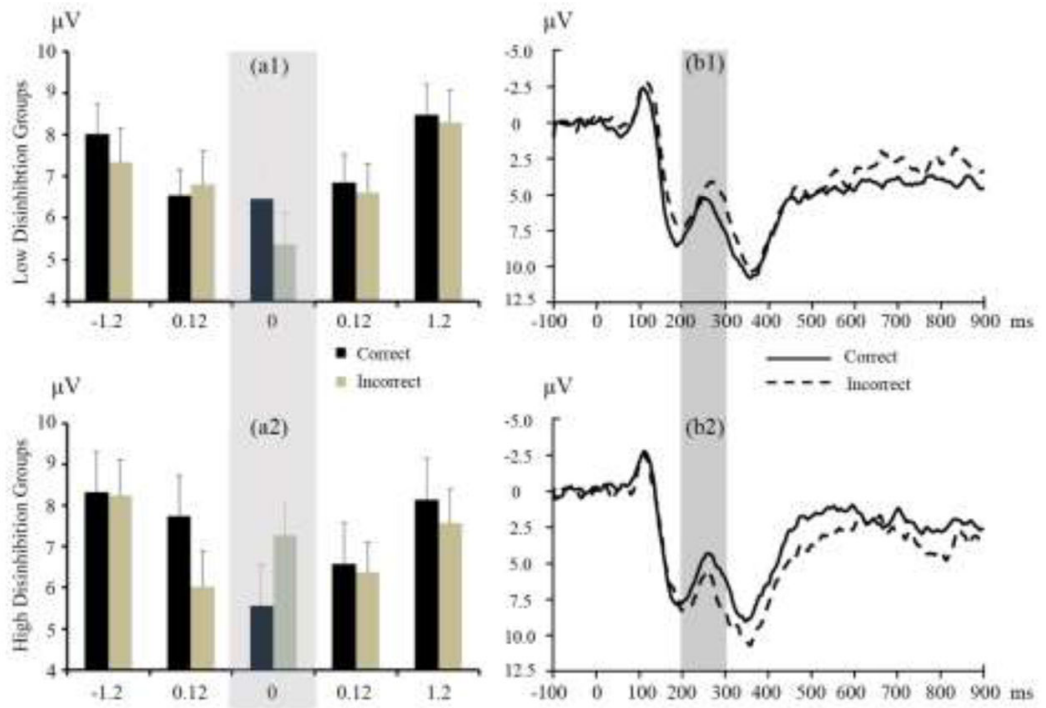

Figure 4.

(a) The illustration of the three-way Incentive $\times$ Correctness $\times$ Disinhibition interaction in the FRN (following outcome presentation). $X$ axis: five different kinds of incentive cue. In the neutral condition (light gray shaped area), correct outcomes elicited a larger FRN than incorrect outcomes in high disinhibition groups; low disinhibition groups showed a reversed pattern, but did not reach significance. (b) The grand-average ERPs evoked by the outcome during the neutral incentive trials at the Fz site, where the FRN reached its maximum. The dark gray shaded area indicates the 200-300 ms time window in which the mean amplitude of FRN was measured. 

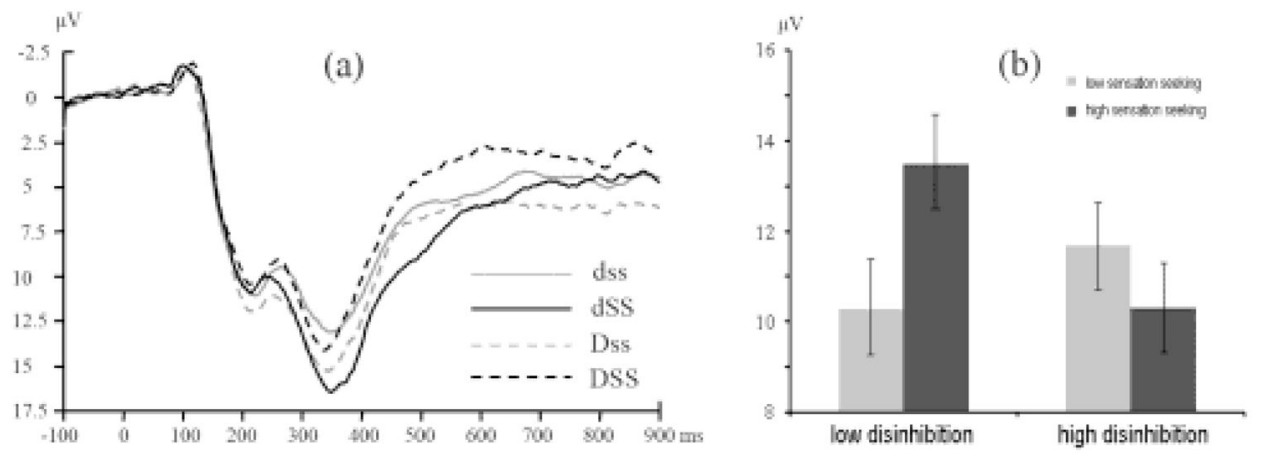

Figure 5.

(a) The grand-average ERPs evoked by the outcome at the $\mathrm{Cz}$ site, where the P3 (following outcome presentation) reached its maximum. The gray shaded area indicates the 300-450 ms time window in which the mean amplitude of P3 was measured. (b) The illustration of the Disinhibition $\times$ Sensation Seeking interaction in the P3 (following outcome presentation). dss: low disinhibition, low sensation seeking group; Dss: high disinhibition, low sensation seeking group; dSS: low disinhibition, high sensation seeking group; DSS: high disinhibition, high sensation seeking group. 


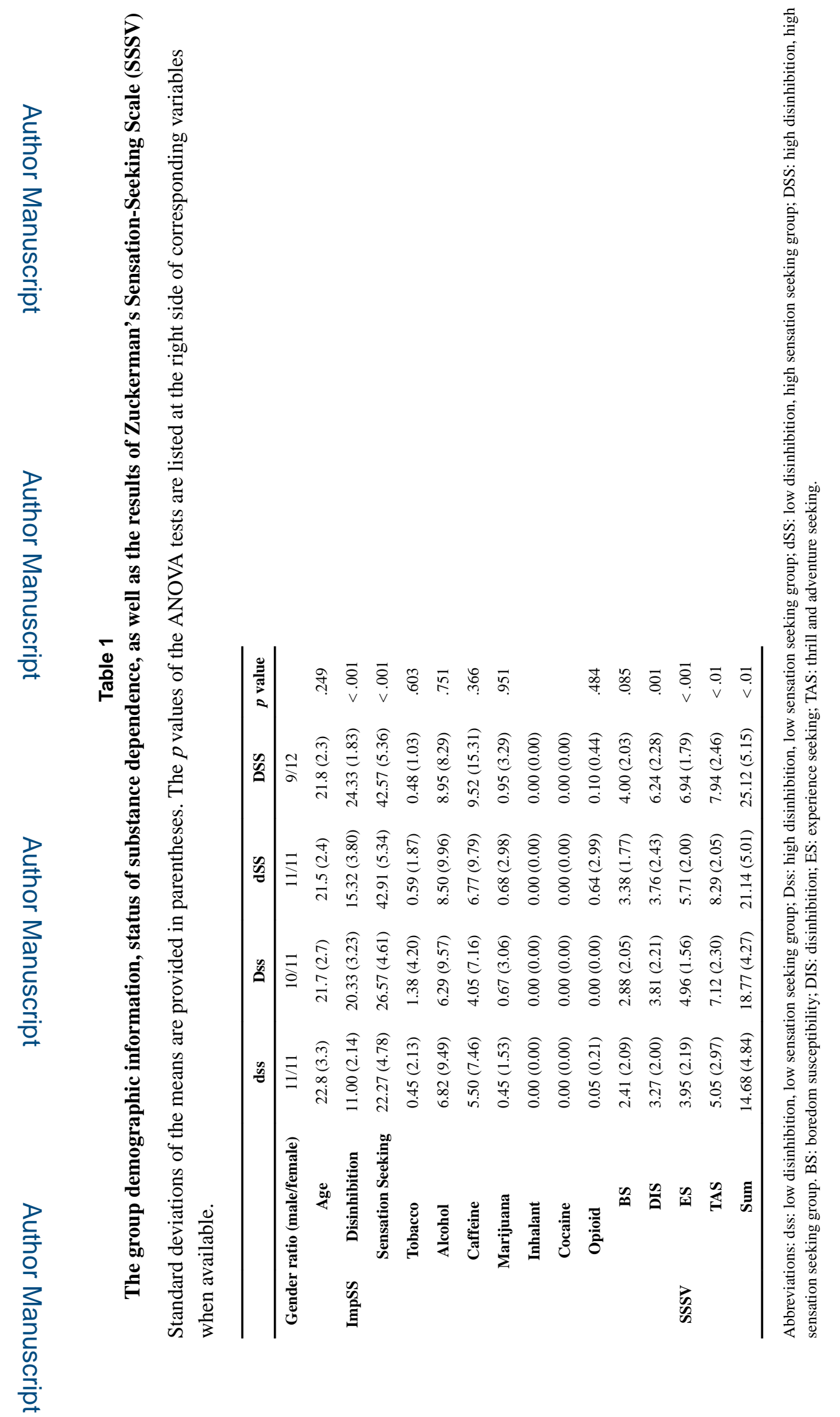

Neuropsychologia. Author manuscript; available in PMC 2018 August 01. 


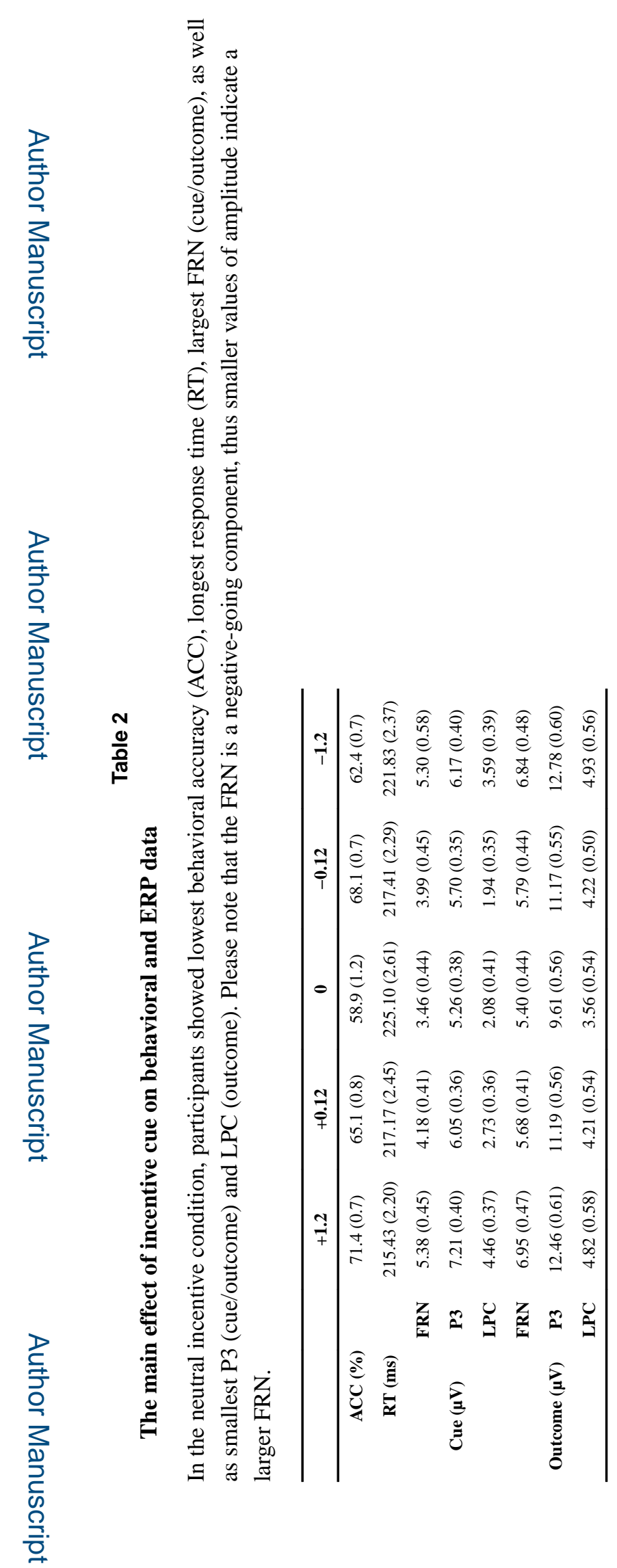

Neuropsychologia. Author manuscript; available in PMC 2018 August 01. 